Original Research Article

\title{
The study of clinical profile and assess the outcome of preterm infants diagnosed to have clinically significant PDA
}

\author{
Bhabagrahi Mallick ${ }^{1}$, Sarthak R. Nayak ${ }^{2 *}$, Subrat Ku. Tripathy ${ }^{2}$
}

\begin{abstract}
${ }^{1}$ Department of Pediatrics, ${ }^{2}$ Department of Biochemistry, IMS and SUM Hospital, Bhubaneswar, Odisha, India

Received: 28 May 2018 Accepted: 26 June 2018

*Correspondence to: Dr. Sarthak R. Nayak, Email: drsarthak.nayak@ gmail.com
\end{abstract}

Copyright: (C) the author(s), publisher and licensee Medip Academy. This is an openaccess article distributed under the terms of the Creative Commons Attribution NonCommercial License, which permits unrestricted noncommercial use, distribution, and reproduction in any medium, provided the original work is properly cited.

\begin{abstract}
Background: Patency of ductus arteriosus is vital for fetal survival. Ductus often fails to close in premature infants called patent ductus arteriosus (PDA). Our objective is to find the clinical profile and assess the outcome of preterm infants diagnosed to have clinically significant PDA.

Methods: 20 infants diagnosed as PDA clinically and confirmed by echocardiography. Symptomatic infants initially treated with fluid restriction and frusemide. Non responders treated with per rectal ibuprofen with dose of 10 $\mathrm{mg} / \mathrm{kg}$ stat followed by $5 \mathrm{mg} / \mathrm{kg}$ x 2 doses at 24 hour intervals. Failure to ductal closure followed by similar second course of ibuprofen. Echocardiography repeated after 72 hours of each therapy. Surgical ligation of ductus was carried after failure to drug therapies. Secondary outcomes during hospitalization were documented.

Results: PDA was diagnosed in seventeen infants during first week and three after seven postnatal day. Mean gestational age and birth weight were $31 \pm 2$ weeks and 1466 \pm 378 grams respectively. Three babies responded well to fluid therapy. Thirteen infants out of seventeen had ductal closure after first course and two to second course of ibuprofen. Two had undergone surgical treatment. Six infants detected with sepsis, five with intraventricular hemorrhage and retinopathy of prematurity. Two developed bronchopulmonary dysplasia. Pulmonary hemorrhage and NEC were found in one each. Two babies died.

Conclusions: PDA is inversely related to gestational age and birth weight. Prostaglandin synthase inhibitors are essential in ductal closure. Surgical ligation is reserved for medical therapy failure. Co-morbidities in PDA are less in well treated babies.
\end{abstract}

Keywords: Echocardiography, Ibuprofen, PDA, Prostaglandin

\section{INTRODUCTION}

In foetal life, the ductus arteriosus plays a major role in shunting the blood from the pulmonary artery (right) to the aorta (left) as lungs impart high vascular resistance. After birth the bloodstream in a patent ductus arteriosus (PDA) will be in a reversed direction due to drop in the pulmonary resistance. A bidirectional shunt in the ductus is found to be common during the first few days of life as vascular resistance in the lungs continues to be quite high for the first postnatal days. At birth the ductus begins to contract and functionally closed within a few days. Usually the ductus obliterates permanently within a few months but it may stay open for up to a year after birth. In infants born prematurely ductal closure is often delayed as compared to term infants. Closure of the DA is due to several mechanisms, the most important being documented as rise in blood oxygen tension at birth and decrease in blood concentration of the prostaglandins $\mathrm{PGE}_{1}, \mathrm{PGE}_{2}$ and $\mathrm{PGI}_{1}{ }^{1,2}$ Oxygen and endothelin are very strong vasoconstrictors and prostaglandins $\mathrm{E}_{2}$ and $\mathrm{I}_{2}$ are strong vasodilators of the ductus arteriosus.

Delayed closure is partly due to immaturity of ductal wall musculature and partly to clinical conditions which halt the normal rise in arterial oxygen concentration at birth. The incidence of PDA is inversely related to gestational age 
and is seen more often in infants with respiratory distress syndrome (RDS) needing ventilation and surfactant or other associated diseases hampering adequate post natal oxygenation. Other notable conditions such as phototherapy for jaundice and over hydration during the first few days of life have also been related to PDA. ${ }^{3}$ The incidence of PDA is $70 \%$ in preterm infants weighing $<1000 \mathrm{~g}$ and 29 weeks gestational age. Increased sensitivity and duration of the ductus to prostaglandins, higher incidence of hypoxia and acidosis, defective smooth muscle migration resulting in compromised anatomical closure in premature as compared to term infants. $^{4}$

PDA is now considered by many experts to be a partly physiological condition which rarely needs treatment. It is supported by several recent studies indicating that the side effects and results of treatment might be more harmful to the infant than the PDA itself. PDA is a major morbidity in prematurity, especially in infants $<28$ weeks. Clinical signs and symptoms of PDA in preterm infants are inconclusive for making an early diagnosis of significant ductal shunting. PDA has been associated with a number of major complications of prematurity. ${ }^{5-8}$

If an infant with a PDA is unable to increase cardiac output to compensate for the blood shunted across the ductus, reversed flow might be seen in the aorta (ductal steal). This will compromise the blood flow to several organs including the vital organs like brain, kidney and intestines. ${ }^{9,10}$

Failure of the PDA leads to significant left to right shunting of blood and undesirable effects, including pulmonary edema and hemorrhage, congestive cardiac failure, clinically manifested with wide pulse pressure and bounding pulses, hypo-perfusion followed by reperfusion elevates the risk of intraventricular hemorrhage (IVH), cerebral vascular accidents, necrotizing enterocolitis (NEC), acute renal failure (ARF), feeding intolerance, poor weight gain, BPD (bronchopulmonary dysplasia) and death. Therefore, diagnosis and appropriate treatment of the PDA is essential to prevent these morbidities. ${ }^{11,12}$

Clinical diagnosis of PDA usually accessed with at least one or more symptoms, including bounding pulses with wide pulse pressure $(>25 \mathrm{~mm} \mathrm{Hg})$, hyperdynamic precordium, an ejection systolic murmur (occasionally pan systolic and continuous murmur) heard best at the $2^{\text {nd }}$ left parasternal area, tachycardia (Heart rate>160/min), worsening respiratory status, edema and/or oliguria. ${ }^{13}$ However, along with clinical diagnosis, the echocardiogram remains the gold standard in confirming the hemodynamically significant PDA. Various studies have disclosed that the echocardiographic criteria of a significant left to right shunt usually precede clinical symptoms by a duration of 2-3 days. This timing is also vitally important in making a decision to treat as within the first $24 \mathrm{~h}$ of life, as approximately $1 / 3^{\text {rd }}$ of PDAs begin to close spontaneously and they do not require any treatment.
Doppler echo is more specific and sensitive for the diagnosis of PDA while an M mode echo is great for assessing the severity of the shunt across the PDA. Radiographic detections are non-specific for the diagnosis of PDA. They comprise of cardiomegaly, upturned left bronchus due to left atrial hypertrophy and pulmonary plethora. ${ }^{14-16}$

Until recently a PDA has been regarded as a condition needing as early and effective treatment as possible. Prophylactic treatment of PDA has also been recommended for the most premature and sickest infants. ${ }^{17}$ First line strategies are employed to close a PDA in a symptomatic preterm infant including careful fluid administration, diuretics and prostaglandin synthetase inhibitors such as ibuprofen and indomethacin. Ibuprofen is found to be an inhibitor of prostaglandin synthesis and is effective in closing the ductus. It is having the equal efficacy as compared to indomethacin with lower side effects. It is also associated with a lower incidence of oliguria and renal compromise. It has been found to have a lesser impact on mesenteric and cerebral blood flow as compared to indomethacin. ${ }^{18}$

Surgical PDA ligation should only be considered when drugs therapy had either failed or contraindicated and may be carried out by thoracotomy or video assisted thoracoscopy. ${ }^{19,20}$

Meta-analyses have shown that there are no significant differences in successful ductal closure using indomethacin or ibuprofen, long or short treatment courses or surgical or pharmacological treatment with regard to the final outcome for the infant. ${ }^{19,21,22}$

\section{METHODS}

The present study was conducted in tertiary care neonatal intensive care unit; Lotus Children's Hospital. It was a retrospective study with one year duration. Medical records of 20 infants who were diagnosed as PDA clinically and confirmed by echocardiography were reviewed. Any preterm infant with a symptomatic PDA diagnosed clinically and confirmed by ECHO criteria irrespective of treatment in the neonatal period ( $<28$ days $)$ were included in study and infants with any associated complex congenital heart disease were excluded from the study group. Sepsis, metabolic and hematological screening was done in all infants.

The clinical diagnosis of PDA is based on the following criteria such as tachycardia (heart rate $>160 / \mathrm{min}$ ), tachypnea (respiratory rate $>60 / \mathrm{min}$ ), high volume pulse, hyperdynamic precordial impulse, murmur which may be continuous and / or systolic. Clinical diagnosis of PDA was confirmed by 2D and Doppler echocardiography prior to starting medical therapy.

Echocardiography criteria for hemodynamically significant PDA are: Ductal diameter of $>1.5 \mathrm{~mm}, \mathrm{LA}$ : AO 
ratio of >1.6, Left to-right shunting of blood, End diastolic reversal of blood flow in the aorta and poor cardiac function

Clinical data were collected includes demographic information, duration of mechanical ventilation, diagnosis of intra ventricular hemorrhage (IVH) accessed by bed side cranial ultrasonography on every preterm infant weight $<1,500$ gram at day 3 and day 7 , necrotizing enterocolitis (NEC) according to Modified Bell's staging criteria, bronchopulmonary dysplasia (BPD), pulmonary hemorrhage, reopening of ductus following three doses of ibuprofen therapy, sepsis was evaluated by clinical symptoms and signs plus a positive bacterial culture in a specimen obtained from normally sterile fluids), periventricular leukomalacia (PVL), retinopathy of prematurity (ROP) as per International Classification of Retinopathy of Prematurity (ICROP), and mortality during hospitalization.

Infants diagnosed with symptomatic PDA were initially treated with fluid restriction and diuretic with frusemide $1 \mathrm{mg} / \mathrm{kg}$ body weight per dose three times a day. Infants who did not respond, per rectal ibuprofen was administered with dose of $10 \mathrm{mg} / \mathrm{kg}$ stat followed by $5 \mathrm{mg} / \mathrm{kg} \times 2$ doses at 24 hour intervals, if there was no contraindication to it. A second course of per rectal Ibuprofen was given to those whom ductus failed to close or reopened. Infants who failed to respond to ibuprofen or had a contraindication to medication were treated with surgical ligation of duct. Echocardiography was repeated in all cases 72 hours after completion of therapy. The study has been approved by the Institutional Ethics Committee.

Results of the study were analysed statistically by Microsoft excel and SPSS 20.0 software.

\section{RESULTS}

Total twenty preterm babies were diagnosed to have symptomatic PDA during the study period. Out of which twelve infants were male $(60 \%)$ and eight $(40 \%)$ were female. Incidence of male to female ratio was 1.5:1. PDA was diagnosed during the first week of life in $17(85 \%)$ babies and in $3(15 \%)$ babies after the 7 th postnatal day. Mean gestational age and birth weight were found to be $31 \pm 2$ weeks and $1466 \pm 378$ grams respectively. PDA was diagnosed in $10(50 \%)$ preterm babies with RDS who had received ventilator support and out of them 7 received surfactant.

The incidence of PDA with respect to the gestational age and birth weight were observed. Maximum incidence (40\%, eight infants) of total PDA born at gestational age of 28-30 weeks whereas only one baby (5\% total) affected PDA born in $<28$ weeks of gestation (Table 1).

Table 1: Prevalence of PDA in relation to birth weight and gestation age.

\begin{tabular}{|lllllll|}
\hline Weight (Gms) & Gestational Age (weeks) & $<28$ & $\mathbf{2 8 - 3 0}$ & $\mathbf{3 1 - 3 3}$ & $\mathbf{3 4 - 3 7}$ & Total \\
\hline$<1000$ & 1 & 2 & 0 & 0 & $3(15 \%)$ \\
\hline $1001-1500$ & 0 & 6 & 3 & 1 & $10(50 \%)$ \\
\hline $1501-2500$ & 0 & 0 & 2 & 4 & $06(30 \%)$ \\
\hline$>2500$ & 0 & 0 & 0 & 1 & $01(05 \%)$ \\
\hline Total & $01(05 \%)$ & $08(40 \%)$ & $05(25 \%)$ & $06(30 \%)$ & $20(100 \%)$ \\
\hline
\end{tabular}

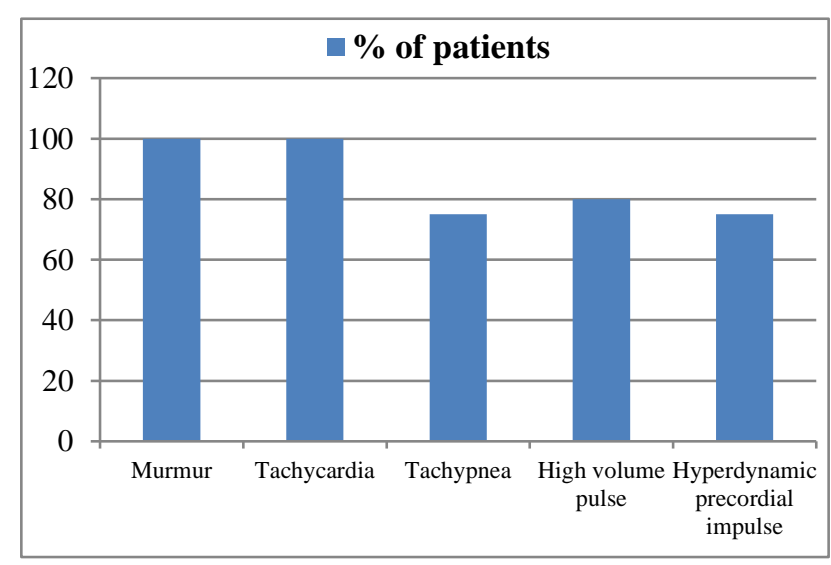

Figure 1: Clinical presentation PDA.

The major clinical presenting features found in PDA infants were as follows: systolic murmur (100\%), tachycardia (100\%), tachypnea $(75 \%)$, bounding pulses $(80 \%)$ and hyperdynamic precordial impulse $(75 \%)$ (Figure 1).

Thirteen $(76.5 \%)$ out of 17 babies had ductal closure after $1^{\text {st }}$ course of ibuprofen. Out the four babies who received $2^{\text {nd }}$ course of ibuprofen after failure to $1^{\text {st }}$ course, two babies $(50 \%)$ responded and had ductal closure but two babies failed to respond and had undergone surgical ligation of duct (Table 2).

Of the three babies who were not given ibuprofen, two improved with fluid restriction and diuretics. The third baby did not receive the drug due to thrombocytopenia. None of the babies who survived had drug related complications. Out of 20 babies, two babies died (10\%). One baby died after the completion of ibuprofen therapy 
due to fulminant sepsis and related complications and the other baby had post surgical complication and sepsis.

\section{Table 2: Response to Ibuprofen and surgical treatment.}

\begin{tabular}{|llll|}
\hline $\begin{array}{l}\text { Treatment } \\
\text { (Closure of } \\
\text { duct by) }\end{array}$ & $\begin{array}{l}\text { No of } \\
\text { patients }\end{array}$ & $\begin{array}{l}\text { Outcome } \\
\text { (Closure) }\end{array}$ & Percentage \\
\hline $\begin{array}{l}1^{\text {st }} \text { Course of } \\
\text { Ibuprofen }\end{array}$ & 17 & 13 & $76.5 \%$ \\
\hline $\begin{array}{l}2^{\text {nd }} \text { Course of } \\
\text { Ibuprofen }\end{array}$ & 04 & 02 & $50 \%$ \\
\hline Surgical & 02 & 02 & $100 \%$ \\
\hline
\end{tabular}

Secondary outcome associated with PDA in relation to gestational age were documented. Out of the 20 babies, six presented with culture positive sepsis, five developed ROP and intraventricular hemorrhage each and two babies developed BPD. Pulmonary hemorrhage and NEC were detected in one baby each. In present study associated comorbidities were predominantly observed in gestational age 28-30 weeks (Figure 2).

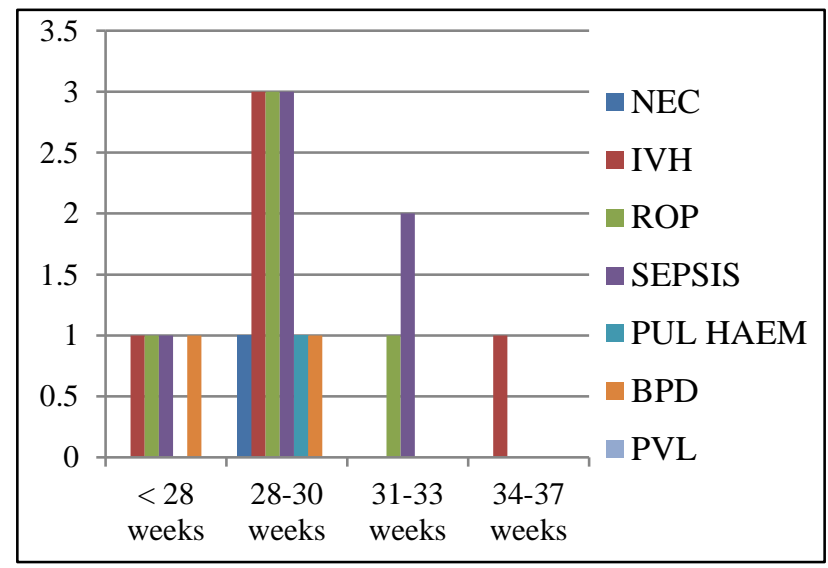

Figure 2: Co-morbidities associated with PDA in relation to gestational age.

\section{DISCUSSION}

PDA is a common accompaniment of prematurity as seen in this study. ${ }^{23}$ The occurrence was also high in low birth weight babies less than 1500 grams. The incidence is inversely related to gestational age as well as birth weight. This was brought out in a large multicentric study which documented an incidence of PDA as $20 \%$ in less than 1750 grams of birth weight, $42 \%$ at $500-999$ grams, $21 \%$ at $1000-1499$ grams and $7 \%$ at $1500-1750$ grams. ${ }^{24}$ The risk was reported to be higher in neonates dependent on ventilator care. ${ }^{25}$ The occurrence of PDA was found to be maximum $(70 \%)$ during the first week of life. Seven out of ten babies, who required ventilatory support for RDS, developed PDA during the first week of life. The opening of PDA during the recovery phase of respiratory distress syndrome is well documented in many studies. ${ }^{26}$ This is attributed to the depletion in cholinergic innervations of the ductus and decreased ductal responsiveness to oxygen and poor myocardial reserves. ${ }^{27}$ PDA is also dependent on the factors which alter the pulmonary vascular resistance.

In those subjected to assisted ventilation, PDA was diagnosed on the criteria of persistent hypoxia, deterioration of ventilatory status requiring changes in the ventilator settings. This is known to be a good indicator of left to right shunt through ductus. ${ }^{28}$ Classical murmur of PDA may not be found always, but it is a high index of suspicion is essential for diagnosing PDA in ventilated neonates. 2-D echocardiography is useful in the diagnosis and confirmation of closure of the ductus. The same clinical and echocardiographic criteria have been used by many workers. ${ }^{29}$

The best time to treat the PDA is preferred, when treatment with COX inhibitors will be most effective while avoiding treatment of infants who may have spontaneous closure of the ductus. ${ }^{8}$ Therefore prophylactic treatment is only indicated in situations where the risk of IVH is very high. If prophylaxis is desired, indomethacin is the treatment of choice, and preferred over ibuprofen lysine as the later fails to show to an effect on IVH. ${ }^{30}$ The current scenario is to treat early pre-symptomatic PDA at two to seven days of life after echocardiogram confirmation. This will curtail the number of babies exposed to $\mathrm{COX}$ inhibitors whose ductus will close spontaneously and at the same time benefit those babies who will respond most favourably to COX inhibitors. ${ }^{31}$

Studies comparing indomethacin and ibuprofen lysine showed equal efficacy rates in ductal closure. ${ }^{32}$ According to these comparative trials, the indomethacin group had statistically significant higher incidence of oliguria and increase creatinine levels. However, ibuprofen lysine will be preferable because of its better toxicity profile. ${ }^{31,33}$ There were no differences in the incidence of NEC, BPD or short-term neurological outcomes in patients receiving either of these COX inhibitors. ${ }^{34}$ Meta-analysis of several comparison studies has reconfirmed these observations. ${ }^{32}$ Medical therapy should still be attempted for PDA closure beyond 7 days of age with the knowledge that treatment may be ineffective, as non-prostaglandin mechanisms are involved in keeping ductal patency by this age.

Surgical ligation should be considered for resistant symptomatic PDA, which fails to respond to medical therapy. Patent ductus arteriosus ligation is a relatively safe procedure (30 day survival $92 \%$ ) but there is substantial late mortality and a high incidence of morbidity in the survivors. Two or more than two courses of prostaglandin synthase inhibitor before surgical ligation tend to enhance oxygen dependence and chronic lung disease. This high risk population requires careful, long term follow-up. A definitive prospective cohort study is lacking. Recent analysis of children at $4 \frac{1}{2}$ and 8 years of age who were treated with indomethacin prophylaxis at birth had shown a favourable neuro-developmental outcome compared to those treated with placebo..$^{35,36}$ 
In this study, $89 \%$ of neonates had successful closure of the ductus after ibuprofen therapy as compared to 79-96\% success rate in various studies. ${ }^{28,36}$ Ibuprofen appears to be safe, as none who responded to the drug in this study had serious drug related complications. All infants who are at a risk of developing PDA should be assessed carefully for the evidence of PDA, as early treatment with ibuprofen will favour the outcome. Echocardiographic evaluation is useful to confirm the diagnosis and also to rule out duct dependent lesions. Ibuprofen therapy is safe and rewarding in pharmacological closure of ductus in symptomatic newborns.

\section{Funding: No funding sources}

Conflict of interest: None declared

Ethical approval: The study was approved by the Institutional Ethics Committee

\section{REFERENCES}

1. Clyman RI. Mechanisms regulating the ductus arteriosus. Biol Neonate. 2006;89:330-5.

2. Spitzer AR, Davis J, Clarke WT, Bernhaum J, Fox WW. Pulmonary hypertension and persistent fetal circulation in the newborn. Clin Perinatol. 1988 Jun $1 ; 15(2): 389-413$.

3. Oh W, Poindexter BB, Perritt R, Lemons JA, Bauer CR, Ehrenkranz RA, et al. Association between fluid intake and weight loss during the first ten days of life and risk of bronchopulmonary dysplasia in extremely low birth weight infants. J Pediatr. 2005 Dec 1;147(6):786-90.

4. Bancalari E, Claure N, Ganzalez A. Patent ductus arteriosus and respiratory outcome in premature infants. Biol Neonate. 2005;88:192-201.

5. Laughon MM, Simmons MA, Bose CL. Patency of the ductus arteriosus in the premature infant: is it pathologic? Should it be treated? Curr Opin Pediatr. 2004;16:146-51.

6. Bose BL, Laughon MM. Patent ductus arteriosus: lack of evidence for common treatments. Arch Dis Child Fetal Neonatal Ed. 2007;92:498-502.

7. Bose CL, Laughon ML. Treatment to prevent patency of the ductus arteriosus: Beneficial or harmful? J Pediatr. 2006;148:713-14.

8. Clyman RI, Chome N. Patent ductus arteriosus: evidence for and against treatment. J Pediatr. 2007;150: 216-9.

9. Perlman JM, Hill A, Volpe JJ. The effect of patent ductus arteriosus on flow velocity in the anterior cerebral arteries: ductal steal in the premature newborn infant. J Pediatr. 1981;99:767-71.

10. Clyman RI, Mauray F, Heymann MA, Roman C. Cardiovascular effects of patent ductus arteriosus in preterm lambs with respiratory distress. J Pediatr. 1987;111:579-87.

11. Cotton RB, Stahlman MT, Dovar I, Catterton WZ. Medical management of smallpreterm infants with symptomatic patent ductus arteriosus. J Pediatr. 1979;2:467-73.
12. Corff KE, Sekar KC. Clinical considerations for the pharmacological management of patent ductus arteriosus with cyclooxygenase inhibitors in premature infants. J Pediatr Pharmacol Ther. 2007;12:147-57.

13. Zahaka KG, Patel CR. Congenital cardiac defects. In Neonatal perinatal medicine - Disorders of the fetus and infants. Eds- Fanaroff AA, Martin RJ. $6^{\text {th }}$ Edn.; 1997:1155-1157.

14. Koch J, Hensley G, Roy L, Brown S, Ramaciotti Cl, Rosenfeld C. Prevalence of spontaneous closure of the ductus arteriosus in neonates at a birth weight of 1000 grams or less. Pediatrics. 2006;117(4):1113-21.

15. Vanhaesebrouck S, Zonnenberg I, Vandervoort P, Bruneel E, Van Hoestenberghe MR, Theyskens C. Conservative treatment for PDA in the preterm. Arch Dis Child Fetal Neonatal Ed. 2007;92(4):244-7.

16. Bose CL, Laughon MM. PDA: lack of evidence for common treatments. Arch Dis Child Fetal Neonatal Ed. 2007;92(6):498-502.

17. Cooke L, Steer P, Woodgate P. Indomethacin for asymptomatic patent ductusarteriosus in preterm infants. Cochrane Database Syst Rev. 2003;2:CD003745.

18. Van Overmeire B, Smets K, Lecoutere D, Van de Broek H, Weyler J, Degroote K, et al. A comparison of ibuprofen and indomethacin for closure of patent ductus arteriosus. N Engl J Med. 2000;343:674-81.

19. Malviya M, Ohlsson A, Shah S. Surgical versus medical treatment with cyclooxygenase inhibitors for symptomatic patent ductus arteriosus in preterm infants. Cochrane Database Syst Rev 2003;3:CD003951.

20. Burke RP, Jacobs JP, Cheng W, Trento A, Fontana GP. Video-assisted thoracoscopic surgery for patent ductus arteriosus in low birth weight neonates and infants. Pediatrics. 1999;104: 27-30.

21. Ohlsson A, Wakia R, Shah S. Ibuprofen for the treatment of patent ductus arteriousus in preterm and/or low birth weight infants. Cochrane Syst Rev. 2005;4:CD003481.

22. Herrera C, Holberton J, Davis P. Prolonged versus short course of indomethacin for the treatment of patent ductus arteriosus in preterm infants. Cochrane Syst Rev. 2007;2:CD003480.

23. Archer N. Patent Ductus Arteriosus in the Newborn. Arch Dis Child. 1993;69:529-32.

24. Ellison RC, Peckham GJ, Lang P, Talner NS, Lerer TJ, Lin L, et al. Evaluation of the preterm infant for patent ductus arteriosus. Pediatr. 1983 Mar 1;71(3):364-72.

25. Cotton RB, Stahlman MT, Kovar I, Catterton W. Medical management of small preterm infants with symptomatic patent ductus arteriosus. Pediatr. 1978;92:467-74.

26. Blanco EC, Siasi B, Cabal LA. Persistent pateney of ductus arteriosus in premature newborn infants, Am J cardiol. 1973;31:120.

27. Heymann MA, Rudolph AM, Silvermann NH. Closure of the ductus arteriosus in premature infants by 
inhibition of prostaglandin synthesis. N EngI J Med. 1976;295:530-33.

28. Yeh TF, Carr I. Pharmacologic Closure of Patent Ductus Arteriosus in Drug Therapy in the Neonatal and Small Infant Year Book Medical Publishers; 1985:116-130.

29. Gentile R, Stevenson G, Dooley T, Franklin D, Kawabori I, Pearlman A. Pulsed Doppler echocardiographic determination of time of ductal closure in normal newborn infants. $\mathbf{J}$ Pediatr. 1981;98:443-8.

30. Aranda JV, Thomas R. Systematic review: intravenous ibuprofen in preterm newborns. Semin Perinatol. 2006;30:114-20.

31. Koch J, Hensley G, Roy L, Brown S, Ramaciotti C, Rosenfield CR. Prevalence of spontaneous closure of the ductus arteriosus in the neonates at a birth weight of 1000 grams or less. Pediatr. 2006;4:1113-21.

32. Thomas RL, Parker GC, Van Overmeire B, Aranda JV. A meta-analysis of ibuprofen versus indomethacin for closure of patent ductus arteriosus. Eur J Pediatr. 2005;164:135-40.
33. Clyman RI. Ibuprofen and patent ductus arteriosus. $\mathrm{N}$ Engl J Med. 2000;343:728-9.

34. Koehne PS, Helfenstein D, Pees C, Walch E, Obladen M. Neurodevelopmental outcome of very low birth weight infants after intervention for patent ductus arteriosus with cyclooxygenase inhibitors. EPAS. 2007;615911:14.

35. Ment LR, Vohr B, Allen W, Westerveld M, Sparrow $\mathrm{SS}$, Schneider KC, et al. Outcome of children in the indomethacin intraventricular hemorrhage prevention trial. Pediatrics. 2000;105:485-91.

36. Ment LR, Vohr BR, Makuch RW, Westerveld M, Katz $\mathrm{KH}$, Schneider KC, et al. Prevention of intraventricular hemorrhage by indomethacin in male preterm infants. J Pediatr. 2004;145:832-4.

Cite this article as: Mallick B, Nayak SR, Tripathy SK. The study of clinical profile and assess the outcome of preterm infants diagnosed to have clinically significant PDA. Int J Basic Clin Pharmacol 2018;7:1593-8. 